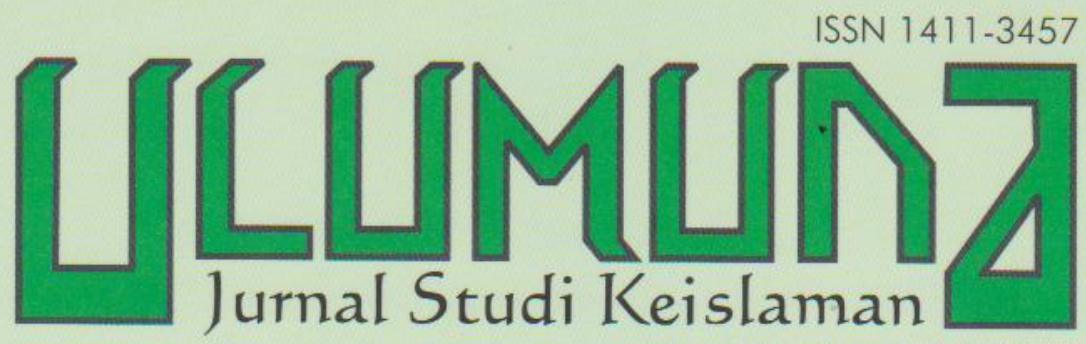

Volume XI• Nomor 1 • Juni 2007

TIELAAM - ISTORIS

PERKENBANEAN OR ENTAUSME ABAD XV-XX

Rendra khaldun

MENXBAK

KENGRASANSIMBOWK ORENTALISE

Iswaknudi

ORIENTALISME

DAN 6PAY DIALOCANTARPERADABAN

Nitivillah

MENCARIE ORENTALISME: MERETAS INAN KE ARAH

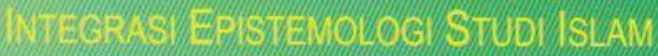
Afrizal

ORENTASM L LBERALSMEISLAM, DAN PENGENBANGAN STUD SLAMDIAIN Alwwan Fanani

MENGURA RAOKALSE ACAMA DU NDONESIA

PASCA OROE BARU Albater Merket Rout 


\section{PEDOMAN TRANSLITERASI}

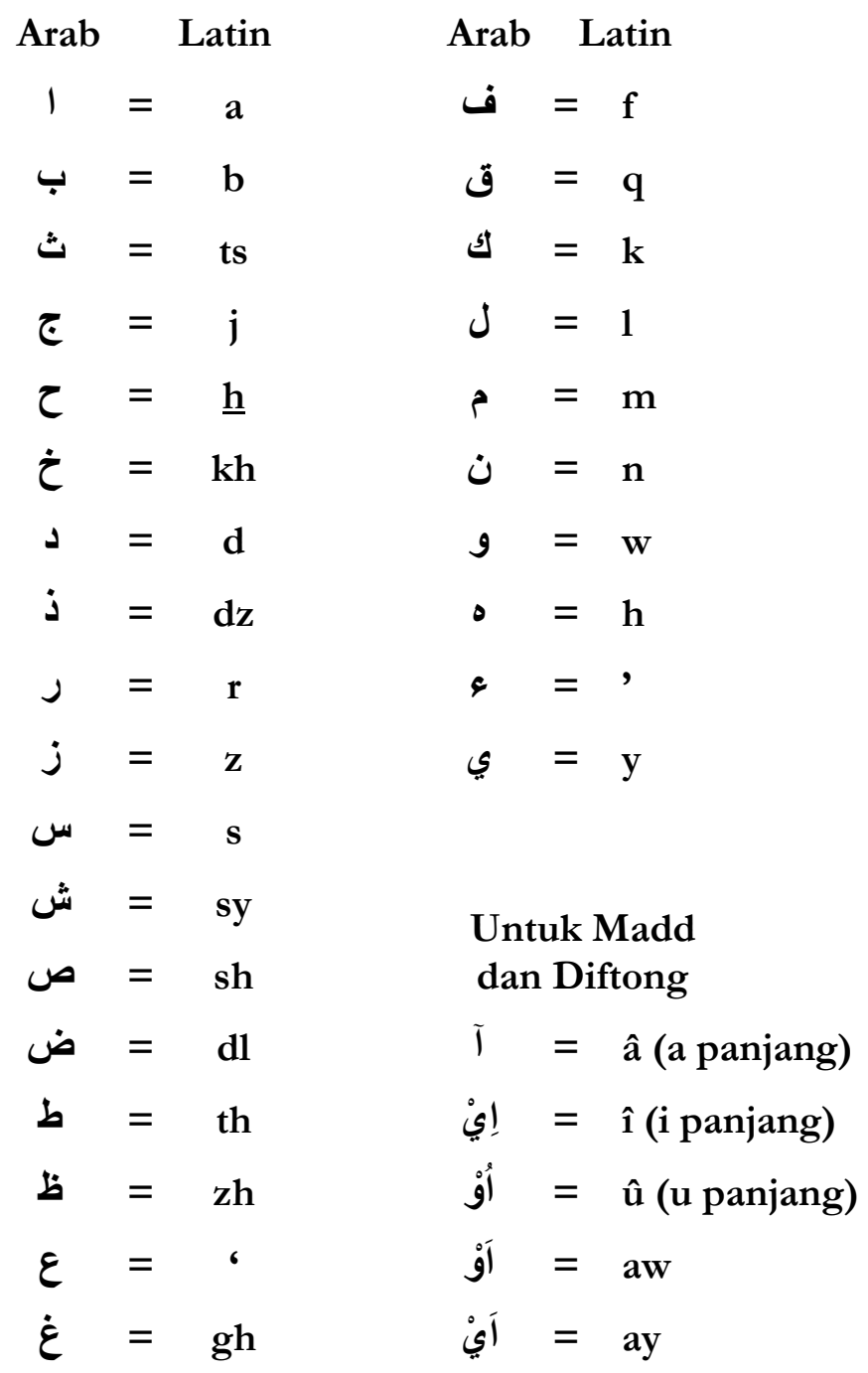


TRANSLITERASI

ANTARAN

UTAMA

Rendra Khaldun

Iswahyudi

Mutiullah

Afrizal

Ahwan Fanani

LEPAS

Miftahul Huda

Ismail Thoib

Abdul Mukti Ro'uf

Ahmad Fathan Aniq

Put

Telaah Historis Perkembangan

Orientalisme Abad XVI-XX • 1-26

Menyibak Kekerasan Simbolik

Orientalisme • 27-52

Orientalisme dan Upaya

Dialog Antarperadaban • 53-72

Mengarifi Orientalisme:

Meretas Jalan ke Arah Integrasi

Epistemologi Studi Islam • 73-92

Orientalisme, Liberalisme Islam, dan Pengembangan Studi Islam

di IAIN • 93-120

Membaca Teks Hadis: Antara Makna

Literal dan Pesan Utama • 121-140

Menggagas Reformasi Pendidikan Islam:

Telaah Filosofis Paradigmatik • 141-156

Mengurai Radikalisme Agama di Indonesia Pasca Orde Baru • 157-176

Rejection of Perda Zakat in East Lombok:

Public Criticism on Public Policy $\bullet 177$ -

198

Ulas BuKu

Fachrizal Halim Self-Criticism to Arab and Muslim

Intellectuals • 199-212

INDEKS 


\title{
TELAAH HISTORIS PERKEMBANGAN \\ ORIENTALISME ABAD XVI-XX
}

\author{
Rendra Khaldun*
}

\section{Abstract}

Studies on relationship between $W$ est and Islam are still important to do till the recent times. The two cultures have been interacting one another for long time and will always do so in the future. To some Muslims point of view, West (Christianity) and East (Islam) become "eternal enemy" to each other. It can be traced in many biased view of orientalist about Islam and Muslims' hatred against them. In this article I explore background of Islamic studies taken by orientalists. At first, orientalists transformed knowledge from Islam world to West through translating Muslim works into Western languages. As effect of Crusade 1, some orientalists do Islamic studies in order to criticize and weaken Islam through their misinterpretation and negative description about Islam. The come of Enlightenment turned some orientalits' views on Islam into more neutral and likeable to Muslim. Their motivation to study Islam is only for the sake of knowledge development.

Keywords: Orientalisme, Islam, Kristen, Barat, Timur.

SEJAK pertamakali muncul, agama Islam merupakan problem bagi Eropa-Kristen. ${ }^{1}$ Orang-orang beriman adalah musuh

${ }^{*}$ Penulis adalah alumnus Program Magister Pascasarjana IAIN Walisongo Semarang Konsentrasi Pemikiran Hukum Islam. e-mail: rakha3@yahoo.com

${ }^{1}$ Islam dijadikan alat propaganda oleh sebagian orientalis untuk menyatukan umat Kristen guna melawan orang-orang Islam dengan berbagai alasan yang mereka buat tentang Islam; juga dijadikan sarana untuk 
menurut mereka. Pada abad VII dan VIII, pasukan yang berperang atas nama penguasa Islam meluas dan masuk ke dalam jantung dunia Kristen. Mereka menduduki provinsiprovinsi kerajaan Bizantium di Syiria, Tanah Suci Mesir, dan terus meluas ke arah barat memasuki Afrika Selatan, Spanyol, dan Sisilia. Penaklukan ini bukanlah semata-mata bersifat militer, melainkan juga diikuti pula dengan konversi agama (Islam).

Hubungan antara umat Islam dan Kristen bukanlah sematamata perang suci, Perang Salib, ${ }^{2}$ atau jihad, tetapi terdapat hubungan perdagangan yang melewati lautan tengah, dan keseimbangan perdagangannya pun berubah dari waktu ke waktu; dari abad XI dan XII. ${ }^{3}$ Selain itu, terdapat pertukaran ide. Pada masa itu lalu lintas terutama bergerak dari daerah-daerah Islam ke wilayah-wilayah Kristen, karya-karya berbahasa Arab tentang filsafat, ilmu pengetahuan, dan kedokteran diterjemahkan ke dalam bahasa Latin dan sampai abad XVI tulisan-tulisan tentang ilmu kedokteran Ibnu Sina diajarkan di universitas-universitas Eropa. ${ }^{4}$ Mulai abad ini, Islam secara implisit mencetak orientalis dan islamolog dalam jumlah yang besar. Para sarjana Barat tersebut menaruh perhatian yang besar pada studi keislaman karena memandang Islam bukan sekedar agama, tetapi juga merupakan sumber peradaban, kekuatan sosial, politik, dan kebudayaan yang patut diperhitungkan.

menakut-nakuti orang Kristen agar bertaubat. Lihat T. Michael, A Muslim Theologian's Response to Christianity: Ibn Taimiya's Al-Jawab al-Shabih (New York: Caravan Book, 1984), vii.

${ }^{2}$ Bahasan yang lebih detail tentang Perang Salib. Lihat Steven Runciman, History of Crusades (Cambridge: Cambridge Univercity Press, 1951).

${ }^{3}$ Untuk Perang Salib yang terjadi setelah tahun 1921 dibahas dalam Aziz S. Atiya, The Crusade in the Later Middle Ages (London: 1938).

${ }^{4}$ Pembahasan yang lebih jelas dan rinci tentang sumbangan orang-orang Islam terhadap perkembangan pengetahuan lihat Muhammad Abdurrahman Khan, Muslim Contribution to Science and Culture (Delhi: Idarah Adabiyah-IDelli, 1880). 
Joseph White dan pemikir sezamannya menggambarkan 200 tahun kesarjanaan Eropa. Studi sistematis pertama tentang Islam dan sejarahnya di Eropa Barat bermula pada akhir abad XVI. Pada tahun 1587, pengajaran bahasa Arab secara rutin dimulai di College de France, Paris; dua professor pertamanya adalah dari kedokteran.

Jadi, sesungguhnya orientalisme sudah memiliki akar tradisi yang cukup panjang di dunia akademik Barat. Namun, orientalisme yang sudah berkembang berpuluh-puluh tahun atau bahkan ratusan tahun itu cenderung dijadikan alat ideologis Barat untuk melakukan hegemoni dan menumbuhkan jenis imperialisme baru di dunia Timur, terutama dunia Islam. ${ }^{5}$ Hegemoni dan penguasaan Barat atas Timur menciptakan kebencian rasial yang semakin memuncak yang tidak hanya diekspresikan sebatas sikap pasif, tetapi juga dalam bentuk usaha-usaha menjawab dan membongkar kepalsuan Barat sudah banyak dilakukan. Nuansa demikian dapat dilihat dalam beberapa karya, misalnya, Orientalism oleh Edward W. Said yang menurut Komaruddin Hidayat, tidak hanya menyajikan kajian yang baik tentang Timur, tetapi juga menyerukan selubungselubung ideologis negatif yang selama ini menghinggapi Barat dalam melihat Timur. Dalam kadar tertentu, Said telah membuka jalan bagi munculnya kesadaran baru tentang perlunya menjadikan Barat sebagai bahan kajian yang disebut oksidentalisme. $^{6}$

${ }^{5}$ Citra dan posisi orientalis kelihatannya memang sulit untuk mengelak dari anggapan bahwa studi dan disiplin ini lebih bersifat ideologis dan merupakan anak kandung imperialisme dan kolonialisme. Apalagi dalam konteks Indonesia, orientalis pernah dijadikan sebagai alat penjajahan Belanda melalui Snouck Hurgrounje untuk mensiasati Aceh dan umat Islam Indonesia secara keseluruhan. Lihat pengantar Komaruddin Hidayat, Pengantar dalam Hasan Hanafi, Oksidentalisme: Sikap Kita Terhadap Barat, ter. M. Najib Buchori (Jakarta: Paramadina, 2000), xvi.

${ }^{6}$ Hidayat, Oksidentalisme ..., xvi. 


\section{Pengertian Orientalisme}

Secara etimologis, orientalisme berasal dari kata "orient" dan "isme". Orient artinya Timur dan isme artinya paham. Menurut Kamus Webster, orientalisme adalah "study of Eastern culture", sedangkan orang yang concern dengan studi ketimuran dinamakan dengan orientalis (a student of Eastern culture). ${ }^{7}$ Dalam pengertian terminologis, secara apik dan elaboratif dikemukakan oleh Salih sebagai kajian yang dilakukan oleh orang Barat terhadap Timur, Islam, yang berkaitan dengan bahasa, kesusasteraan, sejarah, kepercayaan-kepercayaan, perundang-undangan, serta peradabannya dalam bentuk yang sangat umum. Namun, ada juga yang melihat orientalis tidak lebih dari sebuah gerakan intelektual yang berkecimpung dalam penelitian ilmu, tradisi, peradaban, dan kebudayaan Islam dengan tujuan menyelami rahasia, sifat, watak, pemikiran, sebab kemajuan, dan kekuatan masyarakat Islam. ${ }^{8}$

Penjelasan senada, misalnya, dikemukakan oleh Abidin Ja'far yang mendefinisikan orientalisme sebagai suatu ajaran atau paham yang mempelajari dan mengumpulkan segala pengetahuan yang berkenaan dengan bahasa, agama, kebudayaan, sejarah, ilmu bumi, ethnografi, ethnologi, kesusasteraan, dan kesenian yang berasal dari dunia Timur yang mencakup Afrika Utara (Timur Dekat, Timur Tengah, dan Timur Jauh). ${ }^{9}$

Asumsi teoritis yang lebih representatif, dikemukakan oleh Said, orientalisme menyangkut tiga fenomena yang saling terkait. Pertama, seorang orientalis adalah orang yang mengajarkan,

${ }^{7}$ Noah Webster, Webster's New Twentieth Century Dictionary of the English Languge (New York: Simon dan Scuster, 1979), 1261.

${ }^{8}$ Sa'îd al-Dîn al-Sayyid al-Shâlih, Jaringan Konspirasi Menentang Islam, ter. Muhammad Thalib (Yogyakarta: Wihdah Press), 117.

9Abidin Ja'far, Orientalisme dan Studi tentang Bahasa Arab Jakarta: Bina Usaha, 1987), 7. 
menulis atau meneliti tentang Timur, terlepas apakah dia seorang antropolog, sosiolog, sejarawan, dan atau filolog. Dengan kata lain, mereka adalah orang yang mengklaim dirinya memiliki pengetahuan atau pemahaman tentang kebudayaan-kebudayaan Timur. Kedua, orientalisme merupakan mode pemikiran yang didasarkan pada pembedaan ontologis dan epistemologis antara Timur dan Barat. Ini adalah sebuah kategori besar dan hampir tidak berbentuk yang mencakup pemikiran dan tulisan orang yang membagi dunia secara bipolar, Timur dan Barat. Ketiga, dan yang paling signifikan menurut Said, bahwa orientalisme dapat didiskusikan dan dianalisis sebagai institusi yang berbadan hukum untuk menghadapi Timur, yang berkepentingan membuat pernyataan tentang Timur, membenarkan pandanganpandangan tentang Timur, mendeskripsikannya dengan mengajarkannya, memposisikannya, dan kemudian menguasainya. Pendeknya, orientalisme adalah cara Barat untuk mendominasi, merestrukturisasi, dan menguasai Timur. ${ }^{10}$

Kerangka teoritis yang diungkap di atas dapat dipahami, bahwa orientalisme berusaha mempelajari masalah-masalah ketimuran yang menyangkut agama, adat istiadat, bahasa, sastra, dan masalah lain yang menarik perhatian mereka tentang soal ketimuran dengan memproduksi berbagai stigma tertentu tentang dunia Timur. Meskipun riset mengenai periode-periode Timur berjalan intensif dan menghasilkan banyak karya, tetapi tidak dapat melepaskan diri dari bias-bias tersebut. Para sarjana Barat mencoba menunjukkan indikasi-indikasi fanatisme dan sejenisnya dalam kebudayaan klasik Timur yang mereka pandang masih beroperasi hingga kini;11 pergolakan dan perlawanan terhadap Barat secara tandas dicap sebagai manifestasi fanatisme kaum muslim; setiap resistensi atas dominasi Barat dipandang

${ }^{10}$ Edward W. Said, Orientalism: Western Conception of the Orient (London: Penguin, 1991), 2-3.

${ }^{11}$ W. Montgomery Watt, "The Study of Islam by Orientalists", Islamohristiana Journal, vol. 14 (1980), 202-5. 
sebagai konspirasi keji; pan islamisme dilihat sebagai hantu yang menakutkan, meskipun lingkupnya masih sangat lokal. ${ }^{12}$

\section{Sejarah Orientalisme}

Secara historis, studi keislaman yang dilakukan oleh orang Barat bermula dari kajian teks asli dalam bahasa-bahasa Asia yang memerlukan pelatihan khusus. Ada beberapa pendapat yang melatarbelakangi lahirnya orientalis. Pertama, orientalisme lahir akibat Perang Salib atau ketika dimulainya pergesekan politik dan agama antara Islam dan Kristen Barat di Palestina. Permusuhan politik antara umat Kristen dan umat Islam berkecamuk selama pemerintahan Nuruddin Zanki dan Salahuddin al-Ayyubi. Permusuhan itu berlanjut pada masa saudaranya, al-Adil, sebagai akibat dari kekalahan beruntun yang ditimpakan pasukan Islam terhadap pasukan Salib. Semua itu memaksa Barat untuk membalas kekalahan-kekalahannya. ${ }^{13}$

Kedua, sebagian penulis mengembalikan kelahiran orangorang Islam dan orang-orang Kristen di Andalusia, khususnya setelah Alfonso VI menaklukkan Toledo pada tahun $488 \mathrm{H}$ (1085 M). Dari situ, lahirlah gerakan tobat dan penghapusan dosa yang berpusat di Biara Cluny yang didominasi para pendeta Venesia yang dipimpin oleh Santo Peter The Venerable dari Prancis. ${ }^{14}$ Dari biara itu muncul doktrin yang menilai agama Kristen Spanyol telah rusak akibat banyaknya penetrasi unsur Islam. Sebagai tindak lanjutnya, mereka memulai Perang Salib terhadap Kristen Spanyol, lalu terhadap umat Islam Spanyol. ${ }^{15}$

${ }^{12}$ Robert D. Lee, Mencari Islam Autentik dari Nalar Praksis Ikbal bingga Nalar Kritis Arkoun, ter. Ahmad Baiquni (Bandung : Mizan, 1997), 23-5.

${ }^{13}$ Qasim Assamurai, Bukti-bukti Kebohongan Orientalis, ter. Syuhudi Ismail (Jakarta: Gema Insani Press, 1996), 28.

${ }^{14}$ E. F. Kruijf, Peter the Venerable and Islam (Princeton: Princeton Univercity Press, 1964).

${ }^{15}$ William Muir, The Life of Mubammad (Eidenburg: Eidenburg University Press, 1912), 1-63. 
Ketiga, orientalisme lahir karena kebutuhan Barat untuk menolak Islam, untuk mengetahui penyebab kekuatan yang mendorong umat Islam, khususnya setelah jatuhnya Konstantinopel pada tahun 857 H $(1453$ M) serta tibanya pasukan Turki Utsmani ke perbatasan Wina. Islam merupakan benteng yang menghalangi penyebaran agama Kristen. ${ }^{16} \mathrm{Kempat}$, lahirnya orientalisme, khususnya di kalangan ahli teologi, merupakan kebutuhan mereka untuk memahami intelektualitas Semit karena ada hubungannya dengan Taurat dan Injil. Untuk itu, mereka bersungguh-sungguh mempelajari bahasa Ibrani, Aram, Arab, serta kesusastraan bahasa-bahasa tersebut. Sehubungan dengan itu, mereka memandang bahwa penguasaan bahasa Arab sama pentingnya dengan penguasaan bahasa Ibrani untuk menerjemahkan kitab suci dari bahasa Ibrani ke bahasa Latin secara benar. Schultens, seorang orientalis Belanda, berpendapat dalam tesisnya tentang urgensi bahasa Arab dalam menafsirkan Injil. ${ }^{17}$

Kelima, sebagian penulis berpendapat bahwa orientalisme lahir untuk kepentingan penjajahan Eropa terhadap negaranegara Arab dan Islam di Timur Dekat, Afrika Utara, dan Asia Tenggara, yakni memahami adat istiadat dan agama bangsabangsa jajahan itu demi memperkokoh kekuasaan dan dominasi ekonomi pada bangsa-bangsa jajahan. Semua itu mendorong mereka menggalakkan studi orientalisme dalam berbagai bentuknya di perguruan-perguruan tinggi dengan perhatian dan bantuan dari pemerintah mereka. Sebagian yang lain lagi menghimpun semua faktor dan tujuan itu serta menambah sebab-sebab lain yang menunjang atau menyebabkan lahirnya orientalisme dan studi ketimuran. ${ }^{18}$

${ }^{16}$ Albert Hourani, Islam dalam Pandangan Eropa, ter. Imam Baidlowi dan Imam Baihaqi (Yogyakarta: Pustaka Pelajar, 1998), 10.

${ }^{17} \mathrm{~J}$. Brugman and F. Zchroder, Arabic Studies in the Netherlands (Leiden: 1979), 11.

${ }^{18}$ Assamura, Bukti ..., 26-33. 
Orientalisme sebagai disiplin ilmiah yang sadar mulai muncul pada abad XVII sebagai salah satu aliran pemikiran "Pencerahan". Meskipun filsafat dan ilmu Islam menarik minat pelajar, seperti Roger Bacon dan Leibniz, kajian Barat sebelumnya tentang Islam telah ditandai oleh prapengabdian Kristen. Voltaire dan Montaigne menggunakan lokasi muslim untuk membangun utopia dan distopia yang lebih baik, serta untuk mengkritik pemerintahan Eropa dan mengajukan reformasi. Akan tetapi, bidang ini sebagai disiplin akademis yang berpusat pada kajian filologis tentang teks yang katanya formatif mengenai budaya nonEropa, baru muncul sepenuhnya pada masa revolusi Perancis.

Lembaga pertama yang bermisi mempelajari bahasa dan peradaban Asia adalah Ecole des Langues Orientales Vivantes, yang didirikan di Paris pada tahun 1795. Para orientalis Perancis mengembangkan keahlian bahasa dalam bahasa Arab dan bahasa Islam lainnya, serta metode pengajaran Arab dan bahasa Islam lainnya sudah disistematisasi pada waktu itu. Kecenderungan ke arah pelembagaan meningkat selama abad XIX. Di bawah Antoine-Isaac Silvestre de Sacy (1758-1838) dan muridnya, Ecole menjadi lembaga orientalisme terkemuka di Eropa, dan filologi meraih status ilmu pengetahuan dan ilmu budaya manusia.

Pada abad XX orientalisme mencapai puncak kekuasaan dan pengaruh. Pendirian School of Oriental and African Studies pada 1917 di Inggris dan pendirian jabatan akademis dan jurnal baru di Perancis terutama di Ecole des Langues Orientales Vivantes, College de France, Sorbonne, dan Ecole de Hautes Etudes, mengawali fase baru orientalisme dasar. Demikian juga di Jerman, Rusia, dan Italia, didirikan lembaga-lembaga pengetahuan orientalisme yang baru dan penting. Di Perancis misalnya, pada tahun 1927 muncul sebuah jurnal Revue des etudes islamiques, yang disunting oleh Louis Massignon (1883-1962). Inisiatif ini disejajari oleh karya pelar lain, terutama Ignaz Goldziher (1850-1921), 
Christian Snouck Hurgronje (1857-1936), dan Carl Heinrich Becker (1876-1933), Carl Brockelmann (1868-1956), dan Duncan Black Mackdonald (1892-1952).

Setelah Perang Dunia II muncul kajian daerah, terutama Timur Tengah. Pertumbuhan ilmu sosial yang dinamis mempercepat perubahan orientalisme sebagai topik akademis. Para pemuka dalam proses ini, antara lain Claude Cahen (19091991), Philip K. Hitti (1886-1974), H.A.R. Gibb (1895-1971), Gustave E. Von Grunebaum (1909-1972), dan Giorgio Levi Della Vida (1886-1967). Meskipun ilmu pengetahuan orientalisme modern masih dipengaruhi oleh asal usul filologisnya, namun orientalisme telah berevolusi ke berbagai arah akibat berbagai kehadiran lembaga, intelektual, dan politik. ${ }^{19}$

\section{Historisitas Orientalisme dari Masa ke Masa}

Secara umum, kehadiran orientalisme penuh dengan sejarah dendam dan niat penguasaan terhadap budaya lain yang sebelumnya dianggap sebagai ancaman buat eksistensi Barat, khususnya yang menyangkut dunia Timur (Islam). Sejarah orientalisme berawal dari kajian atas karya-karya ilmiah dari karya kaum muslim setelah adanya interaksi dan pergantian kekuasaan wilayah Islam di belahan Barat, Andalus, kepada penguasa Kristen dan Perang Salib di kota-kota suci Islam di daerah Syam dan Palestina. Sebagai dua Bangsa yang berada dalam suasana konflik dengan sendirinya akan sulit melahirkan persepsi yang positif satu sama lain. Akibat Perang Salib, bangsa Barat mendeskripsikan Islam secara negatif. Mereka-Dunia Barat-memandang Islam sebagai agama teror, agama perusuh, dan gerombolan orang-orang yang patut dibenci. Islam juga dipandang sebagai salah satu sekte Yahudi atau Kristen yang sesat.

${ }^{19}$ John L. Esposito (ed.), Dunia Islam Modern, ter. Eva dkk., jilid 4 (Bandung: Mizan, 2001), 212-4. 
Kaum orientalis sejak ratusan tahun banyak menulis tentang Islam, pada umumnya karangan-karangan mereka dinilai negatif oleh umat Islam. Mereka mempelajari Islam dengan tujuan mengkritik, menyerang, dan pada akhirnya-kalau dapatmenghancurkan Islam. Tetapi pembacaan yang yang kritis dan mendalam tentang tulisan-tulisan mereka akan memberikan gambaran yang lain karena tidak semua kaum orientalis mempunyai sikap negatif terhadap Islam. Di antara mereka ada yang bersikap netral dan simpatik terhadap Islam.

Secara garis besar persentuhan Barat-dalam pengertian orientalisme-dapat diklasifikasikan ke dalam beberapa fase, dan masing-masing fase memiliki sudut pandang yang berbeda dalam melihat Islam; Islam sebagai sebuah ajaran in per se dan Islam sebagai obor yang merangsang dan menumbuhkembangkan peradaban dunia.

\section{Masa Klasik}

Islam pada masa klasik merupakan kekuatan super power dunia, di mana Barat berada dalam dark age (masa kegelapan). Kegelapan dan ketertinggalan yang mencengkeram peradaban Barat tersebut mendorong mereka untuk melakukan kontak peradaban dengan dunia Islam yang menjadi corong peradaban pada masa itu. Proses persentuhan atau dialog antarbangsa Barat dengan bangsa Timur (Arab-Islam, India, dan Parsia) terjadi secara langsung maupun tidak langsung. Peradaban Islam pada masa Klasik (650-1250 M) menarik bagi umat nonmuslim pada masa itu. ${ }^{20}$

Penulis-penulis sejarah menerangkan bahwa bangsa Eropa yang menjadi penduduk asli dari Andalusia, pada umumnya tetap berpegang pada agama Kristen, namun banyak dari mereka

${ }^{20}$ Terdapat berberapa pendapat tentang periodisasi sejarah dalam Islam. Untuk lebih jelasnya, lihat Nouruzzaman Shiddiqi, Tamaddun Muslim (Jakarta: Bulan Bintang, 1988), 112. Bandingkan dengan Harun Nasution, Pembaharuan dalam Islam (Jakarta: Bulan Bintang, 1988), 12-4. 
dipengaruhi oleh kultur Islam. Hegemoni peradaban tersebut nampak dalam kehidupan mereka sehari-hari yang menggunakan bahasa Arab, pakaian Arab, adat-istiadat Arab, dan bersekolah di perguruan-perguruan Arab. Bahasa Arab dikenal dan dipakai di kalangan mereka, bukan hanya sebagai bahasa harian, tetapi juga sebagai bahasa ilmiah. Bahkan raja Spanyol sendiri, Raja Aragon, Peter I (W. 1104 M), tidak dapat menulis dan membaca kecuali dengan bahasa Arab. Orang-orang Spanyol Kristen, seperti yang dikatakan Hitti, terpesona pada peradaban Islam yang gemilang. ${ }^{21}$

Bagian-bagian Andalusia yang lepas dari kekuasaan Islam, untuk beberapa abad masih tetap berada di bawah pengaruh peradaban Islam. Tunjuk misalnya Toledo, walaupun sudah dapat dikuasai kembali oleh Alfonso VI pada tahun 1085, namun selama dua abad kemudian masih menggunakan bahasa Arab sebagai bahasa hukum dan bahasa dagang, bahkan uang dicetak oleh Alfonso dengan memakai tulisan Arab; keperluan keagamaan bagi golongan al-musta'ribûn (orang nonArab yang telah mengalami proses arabisasi), al-Kitab-dalam pengertian Injil-diterjemahkan ke dalam bahasa Arab pada tahun $724 \mathrm{M}$ oleh Uskup Johan dari Seville, kemudian disempurnakan oleh Isaac Velasques dari Cordova pada tahun 946 M.22 Di Sisilia pun situasi dan kondisi kultural telah dihegemoni oleh tradisi Arab, tepatnya peradaban Islam yang secara tidak sadar telah menyatu dengan kehidupan Barat Kristen pada masa itu.

Potret kultural Sisilia seperti di atas menarik perhatian raja Normandia, King Roger I, yang pada abad XI akhirnya berhasil merebut kembali Sisilia dari tangan-tangan kaum kafir. Ia mencurahkan perhatian besar pada ilmu pengetahuan sehingga istananya menjadi tempat pertemuan para filsuf, dokter-dokter, dan ahli-ahli Islam lainnya dalam pelbagai disiplin ilmu.

\footnotetext{
${ }^{21}$ Philip K. Hitti, History of the Arabs (London: MacMillan: 1964), 543.

${ }^{22}$ Ibid., 515.
} 
Kebangkitan baru tradisi melek pengetahuan bangsa Barat-yang sebelumnya terjebak dalam lumpur kegelapan-dengan mengangkat orang-orang Islam sebagai guru besar maupun pembesar kerajaan dalam proses transfer serta alih pengetahuan berjalan secara meyakinkan. Hegemoni kultural Islam seperti ini diteruskan oleh putranya, Roger II, dan ternyata lebih banyak dipengaruhi oleh peradaban Islam Klasik. ${ }^{23}$ Peradaban Islam Klasik memiliki daya tarik bukan hanya bagi orang Eropa yang tinggal di bekas daerah Islam, tetapi juga di luar. Banyak penuntut ilmu dari Inggris, Prancis, Jerman, dan Italia datang belajar ke perguruan tinggi dan universitas yang ada di Andalusia. Sebagai contoh misalnya, Gerbert d'Aurillac, yang sempat menjadi santri di Andalusia sebelum menjadi Paus dengan nama Paus Sylvester II di Roma dari tahun 990-1003 M. ${ }^{24}$ Ia menyebarkan informasi tentang kegemilangan peradaban Islam ke Inggris, Lorraine, Salerno, dan terutama Spanyol sendiri.

Propaganda intelektual yang disampaikan d'Aurillac disambut secara gegap gempita oleh para cendekiawan baru Kristen dengan mulai mengorganisir lembaga yang secara spesifik melakukan penerjemahan teks-teks Arab ke dalam bahasa Latin sehingga dapat dibaca dan dipahami secara luas oleh masyarakat baru Eropa yang haus dengan siraman pengetahuan. ${ }^{25}$ Menurut Radinson, yang pertama-tama menyebarkan informasi yang akurat tentang Islam adalah Peter The Venerable, kepala biara Cluny (1094-1156 M). Kunjungannya ke Spanyol dalam rangka mencari informasi, pertama, ia setidak-tidaknya mendengar mengenai agama kaum muslim dan pekerjaan para penerjemah. Kedua, ia ingin menemukan argumen-argumen intelektual yang mendasar, untuk membela agama Kristen dari ahli bid'ah

${ }^{23}$ Ibid., 543.

${ }^{24}$ Najib al-'Aqiqi, Al-Mustasyriqûn, jilid 1 (Kairo: Dâr al-Mâ’arif, 1965), 100 .

${ }^{25}$ Hitti, The Arabs ..., 164-179. 
Kristen, kaum Yahudi, dan kaum muslim. Ketiga, ia sadar benar akan bahaya yang tengah mengancam Gereja, ketika Gereja memasuki abad "keresahan intelektual", skisme-skisme yang destruktif yang makin berkembang. ${ }^{26}$

Seperti diduga, langkah yang ditempuh Peter-menyebarkan informasi yang akurat tentang Islam-mendapat reaksi keras. Salah satunya datang dari Bernard dari Clairvaux (1090-1153 M). Dalam apologinya, Peter mengemukakan argumen-argumen yang sama dengan yang digunakan para teoritikus intelektual ketika mereka diserang kaum "militan" yang kolot. Di Spanyol, Peter kemudian mempekerjakan sebuah tim penerjemah alQur'an untuk menerjemahkan al-Qur'an yang diselesaikan pada 1143. Naskah-naskah hasil terjemahan tersebut kemudian dikenal sebagai Cluniac Corpus. Namun sayangnya, sekalipun naskah tersebut telah tersebar luas, tidak dipakai sebagai landasan untuk melakukan studi keislaman secara serius. Menurut Radinson, hal ini disebabkan karena suasana polemik yang masih sangat kuat bertahan. Jadi, hanya bagian-bagian yang dapat menyokong kekristenan yang diacu dan dianggap penting dari naskah-naskah hasil terjemahan tersebut.

Hal inilah yang menjadi cikal bakal lahirnya orientalisme di kalangan Barat. Bahasa Arab mulai dipandang sebagai bahasa yang harus dipelajari dalam kajian ilmiah dan filsafat, sehingga dimasukkan ke dalam kurikulum perguruan-perguruan tinggi di Eropa, misalnya di Bologna (Italia) pada tahun 1076, Chartres (Perancis) tahun 1117, Oxford 1167, dan Paris 1170. Perhatian Eropa kepada peradaban Islam kian lama kian meningkat. Di Italia, pengajaran bahasa Arab diadakan di Roma pada tahun 1303, Florence tahun 1321, dan Gregoria tahun 1553. Di Perancis, Toulouse tahun 1217, Montpellier tahun 1220, dan Bordeaux tahun 1441. Di Inggris, Cambridge pada tahun 1209.

${ }^{26}$ Maxime Rodinson, "The Western Image, and Western Studies of Islam", ed. Joseph Schacht dan C.E. Bosworth, The Legacy of Islam (Oxford: Oxford Univ Press, 1974), 15. 
Di dunia Eropa lainnya, pelajaran bahasa Arab dimulai sesudah abad XV. ${ }^{27}$ Penerjemahan buku-buku berbahasa Arab ke dalam bahasa Latin akhirnya mulai dilakukan. Generasi penerjemah pertama terdapat nama-nama seperti Constantinus Africanus (W. 1087 M) dan Gerard Cremonia (W. 1087 M). Dalam level penerjemahan karya-karya kaum muslim, buku-buku filsafat dan kedokteran merupakan karya yang paling diminati dan terus di selidiki, buku tentang optik karya Ibnu Haitsâm, merupakan buku pertama para ilmuan muslim diterjemahkan kedalam bahasa Latin. Tokoh-tokoh penting gerakan orientalisme ini adalah John of Sefile, Romanus, Agustinus, dan Adilard. Untuk mempercepat penterjemahan sekolah-sekolah penterjemahan dibuka. Di Toledo, sekolah demikian dibuka oleh Uskup Raymond (1126 M - 1151 M). Pimpinannya ia serahkan kepada Dominicus Gondisalvi, 28 sehingga ilmuan-ilmuan dan sarjanaserjana Barat yang menyertai "misi suci" tersebut dengan leluasa berkenalan dekat dengan sumber-sumber asli peradaban Islam.

Pada fase ini, tujuan orientalisme adalah memindahkan ilmu pengetahuan dan filsafat yang terdapat dalam peradaban Islam ke dunia Eropa. Ilmu pengetahuan dan filsafat itu diambil sebagaimana adanya, seperti keadaaan orang-orang Timur dewasa ini, yang berusaha memindahkan ilmu pengetahuan dan teknologi yang ada di Barat ke dunia Timur.

\section{Masa Pertengahan}

Pada abad XI sampai abad XIII berkecamuk Perang Salib yang secara umum dimenangkan oleh orang Islam. Kekalahan demi kekalahan yang dialami oleh kaum Kristen pada Perang Salib, memotivasi mereka untuk melakukan kajian-kajian ketimuran secara intens. Kalau dulu, kajian ketimuran, murni

${ }^{27}$ Hourani, Islam ..., 9-20.

${ }^{28}$ Rom Landau, The Arabs Heritage of Western Civilization (New York: Arab Information Centre, 1962), 114. 
didasarkan pada kepentingan pragmatis berupa alih pengetahuan dari orang Islam. Namun, pasca kekalahan mereka pada Perang Salib muncul keinginan untuk mengkritik dan menyerang Islam sebagai agama. ${ }^{29}$ Pengarang-pengarang orientalis periode ini, menulis buku-buku yang memberikan gambaran yang salah dan tidak baik tentang Islam. Hal-hal yang sebenarnya yang tidak terdapat dalam Islam, bahkan bertentangan dengan ajaranajarannya mulai disiarkan di Eropa. ${ }^{30}$

Trauma yang membekas akibat Perang Salib, di mana umat Kristen berhadapan dengan umat Islam sebagai musuh, tampaknya telah menyulut semangat apologetik kristiani. Sarjana-sarjana Kristen yang berada di garis belakang peperangan berupaya membuat gambaran-gambaran imajiner untuk mengobarkan semangat kristiani dan kemudian disebarkan ke berbagai kalangan di dalam Kristen. Jadi, bisa dikatakan

${ }^{29}$ Kekalahan dalam Perang Salib yang menyebabkan kota-kota suci Kristen tetap berada dalam daerah Islam dan jatuhnya Eropa Timur ke bawah kekuasaan Islam menimbulkan perasaan pahit bagi bangsa Eropa. Berita tentang jatuhnya Konstantinopel menurut keterangan E. Creasy, menimbulkan perasaan malu, marah, kegegeran, dan kecemasan di kalangan kaum Kristen Barat. Raja-raja bersumpah untuk mengusir kaum "kafir" itu dari sana.

${ }^{30}$ Salah seorang teolog Kristen yang bernama John of Damaskus merupakan pegawai dalam pemerintahan Dinasti Umayyah di Damaskus yang mengkaji Islam secara serius, pendapatnya tentang Islam menjadi sebuah pandangan umum yang diterima pada masa itu "bahwa Islam merupakan cabang atau bid'ah dari Kristen. Islam percaya pada satu Tuhan, tetapi menolak beberapa kebenaran esensial Kristen, dan karena penolakan ini maka kebenaran yang diakui oleh agama Kristen menjadi tidak bermakna. Namun, keyakinan yang aling umum dipegang berada pada ujung spektrum lain: Islam adalah agama yang sesat, Allah bukanlah Tuhan, Muhammad bukanlah seorang nabi; Islam ditemukan oleh orang-orang yang motif dan sifatnya perlu disesalkan dan dipropagandakan dengan pedang". Untuk lebih jelasnya tentang pandangan orang-orang Kristen Eropa tentang Islam pada saat baru berkenalan denagn Islam. Lihat D. J. Sahas, John of Damascus on Islam (Leiden: 1972), 134-141. 
Perang Salib telah memberi andil yang cukup besar dalam menciptakan berbagai kesalahpahaman Barat terhadap Islam, selain telah mendorong munculnya upaya-upaya yang terorganisasi untuk mempelajari agama tersebut melalui kitab sucinya. ${ }^{31}$

Nabi Muhammad digambarkan sebagai seorang yang selalu diserang penyakit epilepsi, gila perempuan, penjahat, pendusta, dan sebagainya sehingga implikasinya agama Islam yang dibawanya bukanlah agama yang benar. Tulisan yang bernada miring juga dikemukakan oleh Carra de Vaux yang mengatakan bahwa Nabi Muhammad digambarkan di Eropa sebagai orang yang tidak bermoral. Selanjutnya, menurut Pijper, orang di Eropa di abad Pertengahan memandang Nabi Muhammad sebagi seorang yang keluar dari agama Kristen, tak beragama, penipu, pendusta, atau pendeknya sebagai seorang penjahat yang penuh dengan lumuran dosa. ${ }^{32}$

Mengenai agama Islam sendiri, di Eropa disiarkan bahwa dalam ajaran Islam terkandung Trinitas; dan dua dari unsurnya adalah Muhammad dan Apollo. Nabi Muhammad disembah dalam bentuk patung yang dibuat dari emas dan perak. Poliandri dibolehkan dalam Islam, maka wanita Islam boleh mempunyai suami lebih dari satu dalam waktu yang sama. Selanjutnya disebut pula bahwa orang Islam mempunyai kewajiban membunuh orang Kristen sebanyak mungkin, karena membunuh orang Kristen merupakan jalan untuk masuk surga. Islam disiarkan dengan pedang, dalam arti pedang diletakkan di leher seseorang, agar ia mau masuk Islam. ${ }^{33}$ Pada abad

${ }^{31}$ Taufik Adnan Amal, Rekonstruksi Sejarah Al-Qur'an (Yogyakarta: FkBA, 2001), 371.

${ }^{32} \mathrm{Al}-$ 'Aqiqi, Al-Mustasyriqûn ..., 692-4.

${ }^{33}$ Surat-surat kabar di Eropa memuat serangkaian tulisan mengenai Islam, yang arah umumnya dapat dilihat dari judulnya The Sword of Islam. Untuk lebih jelasnya, lihat John L. Esposito, The Islamic Threat: Myth or Reality (New York: Oxfod Univercity Press, 1992), 187. 
Pertengahan, Muhammad digagaskan sebagai penipu, pseudopropheta, tukang sihir, serta ajaran al-Qur'an yang didakwahkannya itu tidak lain dari suatu bentuk Kristen yang diselewengkan. ${ }^{34}$

Gagasan-gagasan Barat Abad Pertengahan di atas, yang lebih merupakan mitos dan fiksi imajinatif, memiliki pengaruh kuat di kalangan sarjana Barat pada masa-masa selanjutnya, dan terlihat sulit dienyahkan dari benak masyarakat Barat hingga dewasa ini. Tetapi, konsepsi Abad Pertengahan itu secara sederhana dapat diabaikan karena tidak ditopang dan dilandasi oleh penelitian ilmiah yang serius. Kepentingan utama yang ada di balik penggagasnya lebih bersifat apologetik, karena difokuskan pada pembelaan keyakinan kristiani serta penyemaian rasa percaya diri di kalangan umat Kristen. ${ }^{35}$

\section{Masa Pencerahan}

Periode permusuhan Kristen terhadap Islam mulai meredup dengan munculnya masa Pencerahan (Enlightenment) yang dijiwai oleh keinginan untuk mencari kebenaran. Pada masa ini, kepercayaan pada kekuatan akal meningkat, tradisonalisme diganti dengan rasionalisme. Penelitian yang bersifat rasional dan objektif untuk mencari kebenaran dipergunakan untuk mempelajari agama Islam. Para pemerhati Islam tidak lagi mengada-ada hal yang sebenarnya tidak terdapat dalam Islam. Pada masa ini, mereka mempelajari agama Islam untuk mengetahui Islam yang sebenarnya sehingga bermunculan tulisan ataupun karya yang lebih apresiatif serta positif terhadap Islam. ${ }^{36}$

Sebagai contoh, misalnya tulisan Voltaire, Carlyle, Gibbon, Reiske, Goethe, dan lain-lain mengenai agama Islam, tidak lagi

${ }^{34} \mathrm{Amal}$, Rekonstruksi ..., 55.

${ }^{35}$ Ibid.

${ }^{36 \mathrm{R}}$. W. Southern, Western Viens of Islamin the Middle Ages (Cambridge, Massachusetts: Harvard University Press, 1962). 
mengandung hal-hal yang buruk tentang Nabi Muhammad. Pandangan yang simpatik terhadap Islam tersebut sebagaimana yang diungkapkan oleh Goethe: "Kalau Islam berarti menyerahkan diri, maka kita semua hidup dan mati dalam Islam". Gibbon juga pernah menyatakan bahwa: "Muhammad mempunyai kecerdasan yang alami dan superior yang dibentuk dalam kesunyian, percakapan memperkaya pemahaman, tetapi kesunyian, produk dari kesunyian tersebut berupa al-Qur'an". ${ }^{37}$ Komentar-komentar bernada positif tersebut, disambut secara negatif dan mendapat serangan dan kritik dari kaum Gereja yang tetap memandang Nabi sebagai Nabi pendusta. ${ }^{38}$

Pada dekade ini, Barat kini mulai melihat Islam sebagai agama yang sejalan dengan makin kuatnya kecenderungan rasionalisme di tengah konflik yang kala itu mengarah kepada pertentangan antara dogma gereja dengan rasionalisme. Para saintifik Barat mulai mencari nilai-nilai pokok yang sejalan dengan kecenderungan rasionalisme. Pada abad XVII, sejumlah penulis mulai meninggalkan praduga dan ciri polemis pandangan Abad Pertengahan tentang Islam dan kaum muslim. Richard Simon (1638-1712), seorang Katolik Perancis, dalam Histoire Critique ces Nations du Levant (1984), memaparkan keimanan dan ritus-ritus kaum muslim berdasarkan sebuah karya seorang teolog muslim sendiri. Tulisannya menunjukkan apresiasi mendalam, malah kekagumannya-ketika ia di tuduh Antoine Arnauld (1612-1694) sebagai terlalu objektif terhadap Islam-dengan menasehatinya untuk sejenak menengok ajaranajaran yang luar biasa para moralis muslim. ${ }^{39}$

Cara pandang moralis yang ditempuh Simon, banyak diamini oleh para pemerhati Islam-islamolog atau orientalis-generasi berikutnya. Mereka menyajikan fakta empiris akan apresiasi serta

${ }^{37}$ E. Gibbon, The Decline and Fall of the Roman Empire (London, t.t.).

${ }^{38} \mathrm{Al}$-'Aqiqi, Al-Mustasyriqûn ..., 692-4.

${ }^{39}$ Maxime Rodinson, Europe and the Mistyque of Islam, trans. By Roger Veinus (Seattle\&London: Univ of Washington Press, 1987), 50. 
toleransi yang diberikan oleh kekhalifahan Utsmani terhadap kaum minoritas. Fenomena keagamaan ini, seharusnya menjadi preseden baik yang patut diteladani oleh umat Kristen. Sejalan dengan spirit Abad Pencerahan, Abad Rasionalitas, Islam dipandang sebagai agama yang rasional, berbeda jauh dengan dogma-dogma Kristen yang sering kontradiktif dengan rasio. Agama Kristen, menurut mereka, hanya memiliki konsepkonsep dan ritus-ritus mistis yang minim. Pada sisi lain, mereka memuji Islam karena semangatnya untuk menuju kehidupan yang bermoral, dengan tetap memperhitungkan kebutuhahkebutuhan jasmaniah. Pendek kata, Islam amat dekat dengan deisme yang diimani sebagian besar manusia abad pencerahan. ${ }^{40}$

\section{Masa Kolonialisme dan Imperialisme}

Perang Salib telah usai. Peperangan itu sesungguhnya adalah perang agama. Perang yang dilancarkan oleh imperaliasme Barat tersebut pada hakikatnya untuk membuat umat Islam jatuh tertunduk di bawah cengkeraman penjajahan. ${ }^{41}$ Pada fase ini kolonialisme merupakan "ajudan" para kolonialis dan alat yang paling ampuh untuk mendalami kondisi sosial-historis negerinegeri jajahan baru. Pada tahap ini orientalisme bertukar peran di mana sebelumnya sebagai pengkaji, peneliti, dan pemerhati masalah ketimuran bertukar menjadi penguasaan dan perampasan atas hak-hak Timur yang dilegitimasi lewat kolonialisme. Dunia Timur telah menjadi objek kekuasaan dan kesemena-menaan bangsa yang lebih kuat (Barat) dan bukan lagi menjadi objek studi yang seharusnya.

Namun dalam hal ini, tidak bisa disimpulkan bahwa seluruh orientalis mempunyai niat buruk dalam mengkaji timur terutama Islam karena tidak sedikit orientalis yang mempelajari Islam

\section{${ }^{40} \mathrm{Ibid}$.}

${ }^{41}$ Abdul Fattah, "Dialektika Historis Islam dan Orientalisme: Penilaian Ulang terhadap Karya-karya Orientalisme", Jurnal Akademika, no. 1 (2003), 44. 
murni untuk kepentingan pengetahuan. Dengan demikian muncullah tulisan-tulisan yang mencoba memberikan gambaran sebenarnya tentang Islam, bahkan menolak segala bentuk imperialisme Barat dengan mendukung kemerdekaan yang diperjuangkan oleh negeri yang sedang terjajah.

Dalam konteks Indonesia, hasil studi dan penelitian yang dilakukan Snouck Hurgronje sangat berpengaruh terhadap kebijakan kolonial Belanda supaya lebih lunak terhadap warga pribumi. Horgronje mengkritik banyak kesalahan yang dilakukan oleh para kolonial Belanda dalam berhubungan dengan banyak masalah yang melibatkan kaum muslim, baik yang disebabkan oleh kesalahan informasi maupun ketiadaan pengetahuan. Akibatnya, kebijakan Islam yang dikembangkan oleh Hurgronje menjadi bagian integral politik etis. ${ }^{42}$ Rekomendasi-rekomendasi Hurgronje mengenai kebijakan baru pemerintah kolonial terhadap Islam secara logis mengikuti analisisnya mengenai Islam di Indoensia. Baginya, jalan keluar terhadap persoalan orang Islam sepenuhnya bergantung pada asosiasi kaum muslim, yang merupakan rakyat Belanda sendiri. Jika asosiasi ini tidak berhasil dicapai, tegas Hurgronje, maka kekuatan-kekuatan lain akan mengontrol masyarakat Indonesia. ${ }^{43}$ Sementara yang terkait dengan dukungan politik yang diberikan oleh para orientalis terhadap perjuangan untuk melawan imperiaias dapat dilihat pada E.G. Browne dari Inggris yang mendukung Revolusi Konstitusional di Iran dan Louis Massignon yang mendukung gerakan kemerdekaan Aljazair. ${ }^{44}$

Sekalipun para orientalis pada periode ini berusaha untuk bersikap netral dan menggambarkan secara objektif dunia Islam, namun tidak sedikit juga orientalis menulis hal-hal yang tidak benar tentang Islam bersama kaum kolonialis yang ikut

${ }^{42}$ Alwi Shihab, Membendung Arus: Respon Gerakan Mubammadiyah terhadap Penetrasi Misi Kristen di Indonesia (Bandung: Mizan, 1998), 84.

${ }^{43}$ Ibid., 85.

${ }^{44}$ Fattah, "Dialektika ...", 45. 
melakukan missi Kristen Barat. Target keagamaan ini menurut Mahmud Hamdi Zaqzuq bertujuan untuk melemahkan unsur kekuatan Islam yang menjadi sumber keunggulan pemikiran Islam dengan jalan menebarkan rasa ragu dan was-was terhadap kebenaran pemikiran Islam. Pada saat yang sama, menanamkan persangkaan ideologis bahwasanya agama Islam merupakan derivasi agama Yahudi dan Nasrani. Lebih lanjut dikemukakan, bahwa kolonialisme yang beriringan dengan kristenisasi bertujuan untuk melindungi kelompok Nasrani dari rencana jahat yang mereka lancarkan dan menyembunyikan hakekat eksistensi mereka serta memberikan peringatan kepada mereka akan bahayanya islamisasi bagi agama yang mereka anut. Sedangkan yang terakhir membawa kabar gembira sekaligus hendak mengkrestenisasikan orang-orang Islam. ${ }^{45}$ Dengan demikian, agama-agama yang dianut di Timur termasuk Islam mereka pelajari dengan maksud untuk mempermudah usaha pengkristenan di daerah yang dikuasai Barat.

\section{Masa Modern}

Pada masa ini-kajian ketimuran atau orientalisme pada masa modern-tepatnya abad XX menghadirkan warna yang berbeda dari pola-pola sebelumnya. Para orientalis berusaha untuk menghadirkan pembacaan yang ilmiah dan objektif terhadap Islam. Mereka tidak bergantung hanya pada pembacaan bukubuku di perpustakaan-perpustakaan Barat, tetapi melakukan elaborasi lapangan yang intens untuk mendapatkan pemahaman yang sesungguhnya tentang Islam. Mereka juga melakukan ziarah intelektual dengan kajian kepustakaan ke berbagai perpustakaan di Timur Tengah serta melacak dan mengkaji manuskripmanuskrip kuno yang tersimpan di perpustakaan-perpustakaan resmi atau pribadi yang ada di dunia Timur. Zakaria Hakim

${ }^{45}$ Mahmud Hamdi Zaqzuq, Islam dan Tantangan dalam Menghadapi Pemikiran Barat, ter. Ahmad Sodikin (Bandung: Pustaka Setia, 2003), 86. 
Zakaria menyatakan bahwa pada hakikatnya, banyak dari buku referensi mengenai studi Islam yang kita pakai sekarang muncul dan dapat diperoleh karena usaha-usaha yang dijalankan kaum orientalis Inggris, Perancis, Jerman, Italia, dan sebagainya”. ${ }^{46}$

Periode ini menghasilkan segolongan kaum orientalis yang bersikap simpatik terhadap Islam dan tentunya mempunyai hubungan baik dengan dunia Islam. Tunjuk misalnya H.A.R. Gibb yang mengarang dan memberi perkuliahan dengan menggunakan bahasa Arab. Berdasarkan otoritas keilmuan tersebut, ia diangkat sebagai anggota Al-Majma' al-'Tlm al-'Arab̂̂ yang berpusat di Damsyik dan anggota dari Al-Majma' al-Lughawi yang berkantor di Kairo. Menurutnya, Islam bukanlah agama yang statis; Islam adalah agama yang hidup yang dapat memenuhi kebutuhan rohani dan intelektual jutaan umat manusia. Tentang figur Nabi Muhammad, ia menyatakan: "Nabi Muhammad mempunyai akhlak dan budi pekerti luhur. Akhlak mulia inilah yang mendorong penduduk Madinah untuk meminta bantuannya dalam mengurus persoalan-persoalan. Dalam masa 1500 tahun tidak satu manusia pun yang dapat membawa satu buku yang demikian kuat dan demikian besar pengaruh emosionalnya seperti al-Qur'an sekalipun al-Qur'an tidak menjelaskan ajaran-ajaran Islam dengan cara sistematis, tetapi dari dalamnya dapat dikeluarkan satu kumpulan ajaranajaran yang tidak saling bertentangan. ${ }^{47}$

Seorang Orientalis lain adalah Louis Massignon. Ia juga diangkat sebagai anggota Al-Majma' al-Tlm al-'Arabî yang berpusat di Damsyik dan anggota dari Al-Majma' al-Lughawi yang berkantor di Kairo. Ia pernah mengikuti kuliah di Universitas Al-Azhar sebagai pendengar dan pernah menjadi dosen Sejarah Filsafat Islam di Universitas Kairo. Menurut Muhammad al-

46Zakaria Hakim Zakaria, Al-Musytasyriqûn wa Al-Islâm (Kairo: Dâr alKutub Al-‘Arabiyyah, 1965), 168.

${ }^{47}$ H.A.R. Gibb, Mohammedanism (London: Oxford Univercity Press, 1965), 34-53. 
Ghallâb, keahliannya dalam bidang tasawuf atau mistisisme Islam, terutama mengenai tasawuf al-Hallâj, merupakan referensi yang bermutu tinggi dan semestinya diterjemahkan ke dalam bahasa Arab. ${ }^{48}$ Dalam tulisan-tulisannya, ia mengatakan, berkat tasawuf, Islam menjadi agama internasional serta mempunyai pengikut di seluruh belahan dunia. Hasil usaha kaum sufi dalam menyiarkan Islam lebih besar dari hasil usaha yang dijalankan melalui ekspansi politik, karena kaum sufi lebih dapat memahami ajaran Islam mengenai persaudaraan seluruh umat manusia. W.C. Smith juga mempunyai pengetahuan yang dalam tentang Islam. Ia adalah pendiri Institut Pengkajian Islam di Universitas McGill di Montreal, Kanada. Menurutnya, Tuhan ingin menyampaikan risalah kepada manusia. Untuk itu Tuhan mengirim rasul-rasul dan Nabi Muhammad adalah salah satu dari rasul-rasul Allah. Risalah yang ingin disampaikan Tuhan ialah norma-norma akhlak dan syariat. ${ }^{49}$

\section{Catatan Akhir}

Pada mulanya, hubungan antara Barat dan Islam begitu harmonis. Hal ini bisa dilihat dari ketertarikan orang-orang Barat dengan peradaban Islam klasik yang ditandai dengan aktivitas penerjemahan yang dilakukan oleh orang Barat terhadap ilmuilmu yang ditulis orang Islam, bahkan bahasa Arab dijadikan bahasa tulis dan lisan orang-orang yang berada di sebagian wilayah Eropa. Namun, apresiasi dan penghargaan terhadap peradaban Islam berubah menjadi pertikaian politik antara Kristen dan Islam menimbulkan yang Perang Salib.

Tidak mengherankan, antara orang-orang Kristen dan Islam terperangkap dalam suasana peperangan. Kedua entitas peradaban tersebut, lebih sering bermusuhan daripada bersikap

${ }^{48} \mathrm{Muh}$ hammad Ghallâb, Nadlarat al-Isytisyrâqiyyah fî Al-Islâm, (Kairo: Dâr al-Kutub al-'Arabiyyah, t.t.), 9 .

${ }^{49}$ W. C. Smith, Islam in Modern History (Mentor Book: 1964), 97. 
sebagai sesama penganut agama Samawi yang bertujuan untuk mematuhi dan mengabdi pada Tuhan. Bagi Kristen, Islam terbukti sebagai sebuah ancaman ganda; secara agama dan secara politik, begitu juga sebaliknya. Permusuhan antara Islam dan Kristen juga terjadi melalui tulisan-tulisan, di mana orang-orang Barat menghujat Islam dan Muhammad, begitu juga sebaliknya dengan Islam. Hal ini masih berlangsung terus sampai abad XVI. Memasuki abad XVII citra Barat tentang Islam mulai berubah seiring dengan datangnya masa pencerahan yang mengedepankan rasionalitas dan keilmuan yang didasarkan pada data dan fakta. Beberapa orientalis berusaha melihat Islam dengan objektif, bahkan tidak sedikit dari temuan-temuan orientalis yang memberikan kontribusi bagi kemajuan dan perkembangan keilmuan Islam sendiri. Wa al-Lâh a lamu bi alshawâb.

\section{Daftar Pustaka}

Abdul Fattah, "Dialektika Historis Islam dan Orientalisme: Penilaian Ulang terhadap Karya-karya Orientalisme", Akademika, no. 1, (2003).

Abidin Ja'far, Orientalisme dan Studi tentang Bahasa Arab (Jakarta: Bina Usaha, 1987).

Albert Hourani, Islam dalam Pandangan Eropa, ter. Imam Baidlowi dan Imam Baihaqi (Yogyakarta: Pustaka Pelajar, 1998).

Alwi Shihab, Membendung Arus: Respon Gerakan Muhammadiyah terhadap Penetrasi Misi Kristen di Indonesia (Bandung: Mizan, 1998).

Aziz S. Atiya, The Crusade in the Later Middle Ages (London: 1938).

D. J. Sahas, John of Damascus on Islam (Leiden: 1972).

E. Gibbon, The Decline and Fall of the Roman Empire (London, t.t.).

E. F. Kruijf, Peter the Venerable and Islam (Princeton: Princeton University Press, 1964). 
Edward W. Said, Orientalism: Western Conception of the Orient (London: Penguin, 1991).

H. A. R. Gibb, Mohammedanism (London: Oxford Univercity Press, 1965).

Harun Nasution, Pembaharuan dalam Islam (Jakarta: Bulan Bintang, 1988).

Hasan Hanafi, Oksidentalisme: Sikap Kita Terhadap Barat, ter. M. Najib Buchori (Paramadina: Jakarta, 2000).

J. Brugman and F. Zchroder, Arabic Studies in the Netherlands (Leiden: 1979).

John L. Esposito (ed.), Dunia Islam Modern, ter. Eva, dkk., jilid 4 (Bandung: Mizan, 2001).

, The Islamic Threat: Myth or Reality (New York:

Oxfod Univercity Press, 1992).

Mahmud Hamdi Zaqzuq, Islam dan Tantangan dalam Menghadapi Pemikiran Barat, ter. Ahmad Sodikin (Bandung: Pustaka Setia, 2003).

Maxime Rodinson, "The Western Image, and Western Studies of Islam", ed. Joseph Schacht dan C.E. Bosworth, The Legacy of Islam (Oxford: Oxford Univ Press, 1974). , Europe and the Mistyque of Islam, trans. By Roger Veinus (Seattle\&London: Univ of Washington Press, 1987).

Muhammad Abdurrahman Khan, Muslim Contribution to Science and Culture (Delhi: Idarah Adabiyah-I-Delli, 1880).

Muhammad Ghallab, Nazarat Isytisyraqiyah fi al-Islam (Kairo: Dâr al-Kutub al-'Arabiyyah, t.t.).

Najib al-'Aqiqi, Al-Mustasyriqûn, jilid 1 (Kairo: Dâr al-Mâ'arif, 1965).

Noah Webster, Webster's New Twentieth Century Dictionary of the English Languge (New York: Simon \& Scuster, 1979).

Nouruzzaman Shiddiqi, Tamaddun Muslim (Jakarta: Bulan Bintang, 1988).

Philip K. Hitti, History of The Arabs (London: MacMillan, 1964). 
Qasim Assamurai, Bukti-bukti Kebohongan Orientalis, ter. Syuhudi Ismail (Jakarta: Gema Insani Press, 1996).

R. W. Southern, Western Views of Islamin the Middle Ages (Cambridge, Massachusetts: Harvard Univercity Press, 1962). Robert D. Lee, Mencari Islam Autentik dari Nalar Praksis Ikbal bingga Arkoun, ter. Ahmad Baiquni (Bandung: Mizan, 1997).

Rom Landau, The Arabs Heritage of Western Civilization (New York: Arab Information Centre, 1962).

Sa'îd al-Dîn al-Sayyid al-Shâlih, Jaringan Konspirasi Menentang Islam, ter. Muhammad Thalib (Yogyakarta: Wihdah Press).

Steven Runciman, History of Crusades (Cambridge: Cambridge University Press, 1951).

T. Michael, A Muslim Theologian's Response to Christianity: Ibn Taimiya's Al-Jawab al-Shabih (New York: Caravan Book, 1984).

Taufik Adnan Amal, Rekonstruksi Sejarah Al-Qur'an (Yogyakarta: FkBA, 2001).

W. Montgomery Watt, "The Study of Islam by Orientalists", Islamohristiana Journal, Vol. 14 (1980).

W. C. Smith, Islam in Modern History (Mentor Book: 1964).

William Muir, The Life of Mubammad (Eidenburg: Eidenburg Univercity Press, 1912).

Zakaria Hakim Zakaria, Al-Musytasyriqûn wa al-Islâm (Kairo: Dâr al-Kutub Al-‘Arabiyyah, 1965). 